\title{
Dynamics of agrochemical properties of gray forest soil of the Western Siberia's sub-boreal zone affected by a long-term agricultural exploitation
}

\author{
D.I. Eremin*, and E.P. Renev
}

Tyumen Research Centre, Siberian branch of the Russian Academy of Sciences, Tyumen, Russia

\begin{abstract}
We studied the changes in the agrochemical properties of the gray forest soil in the territory of Western Siberia's sub-boreal zone affected by the long-term use of the organomineral fertilizers in the grainfollow-row crop rotation and in its absence. We used virgin areas of gray forest soil situated in the immediate proximity to the fields as a control. The anthropogenic changes of morphological features throughout the gray forest soil profile were identified based on the use of fixed permanent plots laid down in 1960. This paper describes the dynamics of the actual, exchange, and hydrolytic acidity as well as the amount of absorbed bases, together with the base exchange capacity and the degree of base saturation. The study of arable gray forest soil for the period 1960-2020 was performed. This provided an opportunity to identify the causes of its chemical degradation in the sub-boreal zone of the Trans-Urals under the conditions of a plant residue shortage. The systematic use of mineral fertilizers affects the base exchange capacity and triggers an increase in the arable layer's acidity. The use of an organic fertilizer system stabilizes the chemical properties of gray forest soil.
\end{abstract}

\section{Introduction}

The intensification of agriculture in Western Siberia has begun in the middle of the XX century and continues to the present time. Over the years of the planned economy in the USSR, the systems for increasing the fertility of Siberian soils were scientifically proved and developed $[1,2,3]$. The switch to a market economy promoted the transformation of the agricultural system in the direction of increasing the productivity of arable land with a simultaneous reduction in the product cost. This caused many farms to reject a set of measures to increase the fertility of arable land and increase the anthropogenic load on the soil $[4,5,6]$.

The implication of soils in farming business necessarily results in a change in their chemical properties and the transformation of morphological features. There is enough data to show that because of human activity, soil fertility is being sharply reduced. Meanwhile,

\footnotetext{
* Corresponding author: soil-tyumen@yandex.ru
} 
there are facts of improvement of the soils involved in agricultural turnover. This is particularly true of podsolic and gray forest soils.

It should be noted that agrochemical land degradation, unlike physical degradation, has no visible signs, which makes the issue more serious. It is possible to notice this degradation only with systematic monitoring covering a large period. The monitoring frequency in the agrochemical service is 5 years, which is enough to analyze the availability of nutrients and acid-base characteristics of the soil. Nevertheless, to give an answer on the dynamics of humus reserves or the capacity of cation exchange, it requires up to 10 such periods, which in total is at least 50 years.

The agrochemical degradation involves a disruption of the balance between the nutrients available to plants; leaching of calcium and magnesium cations, which provokes acidification of the root zone. The most meaningful element of soil degradation is believed to be the reduction of humus reserves and the deterioration of its quality, which is expressed in the ratio of carbon to nitrogen and the ratio of humic acids to fulvic acids $[7$, 8].

Notwithstanding the short period of use of gray forest soils of the Western Siberia subboreal zone, a strong technogenic load has resulted in serious changes in agrochemical properties. The most significant factors affecting the soil are mechanical processing and fertilization. The mechanism of their impact on the soil is different. However, it is generally known that in the absence of scientific justification, the degradation only increases.

The researches ' opinions were divided on the influence of mineral fertilizers on the chemical properties of soils. Some of them believe that mineral fertilizers directly acidify the soil; others - that there is no reliable effect of acidification [9, 10]. However, everyone unanimously agrees that an increase in yield due to mineral fertilizers increases the removal of biophilic cations, particularly calcium and magnesium, which results in a reduced amount of exchange bases with a simultaneous increase in the hydrolytic acidity. This negatively affects the structure formation and degrades the agrophysical properties of arable land.

A long-term plowing without systematic use of organic fertilizers significantly results in a reduced humus content of gray forest soils. The reason for this is the enhanced aeration of the arable layer, which stimulates the aerobic microflora that mineralizes an organic matter. For the stabilization of the humus condition of arable land in the absence of organic fertilizers, an accurate calculation is required, accounting for the intake of plant residues (including plowed straw) and the microflora activity. Thus, the optimal solution for agricultural enterprises is the use of an organomineral fertilizer system, in which the amount of plant residues that exceeds the mineralization of organic matter by $20-40 \%$ annually enters the soil. Our previous studies have demonstrated that the plowed straw is sufficient for a positive humus balance only when the crop is formed from 3.0 to $4.0 \mathrm{t} / \mathrm{ha}$. In other cases, there was a negative humus balance.

According to the researchers, the negative impact of mineral fertilizers can be decreased by using organic fertilizers. This is particularly important for gray forest and podsolic soils, where the chemical properties are initially unfavorable for plants. The favorable effect of the systematic use of organic fertilizers on low-productive soils has been repeatedly proven and cannot be questioned. Nevertheless, a wave of agrarian reforms took place in the Russian Federation at the end of the XX - beginning of the XXI centuries, which resulted in the extinction of animal husbandry in medium and small farms. Huge livestock complexes of up to two or three thousand heads of cattle replaced them. The manure and its compost began to accumulate on a relatively small territory, which enterprises are trying to make in the fields adjacent to the farms. As a result, a significant proportion of arable land began to experience an acute shortage of organic matter, which contributed to agrochemical degradation countrywide. 
In Russia, there has been a decline in chemical amelioration of agricultural land, which, with the long-term use of mineral fertilizers, resulted in acidification. It is especially visible in the distribution zone of gray forest soils, which have a genetic tendency to increase acidity. Human agricultural activity has only accelerated this process.

Consequently, the combination of all these reasons, the challenge of agrochemical degradation has sharply worsened, and research on the study of agrochemical degradation has become relevant countrywide.

\section{Materials and methods}

The research was performed on the territory of the Tyumen region in the sub-boreal zone of the Trans-Urals. The studied soil is gray forest podzolic medium loamy, typical for Western Siberia. The field investigations were performed on the territory of the Yurginsky district. The laboratory studies were performed at the Department of Soil Science and Agrochemistry of the State Agrarian University and the Agrochemical Laboratory of the Research Institute of the Northern Trans-Urals branch of the Siberian Branch of the Russian Academy of Sciences.

In 1960, under the leadership of Professor L. N. Karetin, soil studies were conducted with the laying of 6 full-profile soil sections. The agrophysical, physico-chemical and water-physical properties on arable land and virgin land were considered. In the field experiment, the following scheme was used: Control (without fertilizers); organic fertilizer system - once every three years, half-ripe manure was plowed to a depth of $20-22 \mathrm{~cm}$. The plowing up was carried out under the forecrop of the first group (cropped fallow; corn for silage). The research was performed in a grain-follow-row rotation with alternating crops: cropped fallow (pea - oat mixture) - spring wheat - oats-corn-barley-oats.

Since 1960, manure has been applied every three years for annual grasses and corn at doses of $75 \mathrm{t} /$ ha. From 1996 to 2007, the dose of organic fertilizers was lowered to $30 \mathrm{t} /$ ha due to organizational and economic reasons. From 2008 to 2019, a half-ripe manure was used differentially: for annual grasses in doses of $90 \mathrm{t} / \mathrm{ha}$; for corn-75 $\mathrm{t} / \mathrm{ha}$. A total of 1,350 $\mathrm{t} / \mathrm{ha}$ of manure was applied in the period from 1960 to 2019, which corresponded to the annual application of $23 \mathrm{t} /$ ha.

Mineral fertilizer system, which provided for the annual application of $\mathrm{N}_{65} \mathrm{P}_{30} \mathrm{~kg} / \mathrm{ha}$ for grain crops. In the period from 1960 to 1996 for rotation of grain crops (wheat, oats and barley) they applied $\mathrm{N}_{65} \mathrm{P}_{30} \mathrm{~kg} / \mathrm{ha}$. From 1997 to 2007, the doses for grain crops were reduced by $\mathrm{N}_{30} \mathrm{~kg} / \mathrm{ha}$ due to economic reasons. From 2009 to the present time, it was decided to apply $\mathrm{N}_{60} \mathrm{P}_{30}$ for spring wheat, and for all other grain crops $-\mathrm{N}_{30} \mathrm{~kg} / \mathrm{ha}$. Over the years of experience, $1980 \mathrm{~kg}$ of nitrogen and $720 \mathrm{~kg}$ of phosphorus were used. The fertilizers were applied in the spring in the form of ammonium nitrate and double superphosphate, which were cut with mulcher seeders before grain crops sowing.

The research program included the analysis of agrochemical properties for the entire soil profile. The sampling was performed after two crop rotations: $1960 ; 1971 ; 1983 ; 1995$; 2007; 2019. For the study of anthropogenic changes in morphological features in 1989 and 2019, full-profile soil sections were re-laid on arable and virgin land, which dimensionally corresponded to the sites of the initial sections of 1960. The staff of the Department of Soil Science and Agrochemistry carried out the investigations, namely, L. N. Karetin, A. G. Karyakina, G. D. Pritchina, E. P. Renev and D. I. Eremin.

The agrochemical studies were conducted by the following methods: the soil solution reaction and exchange acidity (potentiometrically); hydrolytic-by Kappen method. The sum of the exchange bases is calculated according to Kappen-Gilkovitz method; the capacity of the cation exchange and the degree of base saturation 


$$
\begin{aligned}
& \mathrm{BEC}=\mathrm{S}+\mathrm{HA} \\
& V=\frac{S}{B E C} * 100 \%
\end{aligned}
$$

Where EKO - a base exchange capacity, cmol (eq) $/ \mathrm{kg}$;

$\mathrm{S}$ - the sum of exchange cations, $\mathrm{cmol}(\mathrm{eq}) / \mathrm{kg}$;

$\mathrm{HA}$ - hydrolytic acidity, cmol (eq) $/ \mathrm{kg}$;

$\mathrm{V}$ - the degree of base saturation, \% from EKO.

The research results were processed by the method of descriptive statistics using Microsoft Excel.

The aim of the study is to analyze the influence of long-term agricultural use of gray forest soil on the change of its agrochemical properties.

\section{Results}

The description of morphological features of the gray forest soil profile on virgin land showed that the current process of soil formation is presented by podzolization and illuviation $[10,11]$. The gray forest soil is distinguished by well-developed genetic horizons and has the following formula for the profile structure: AO-AY-BEL-Bt-Bt $t_{(\mathrm{Ca})}-\mathrm{C}_{(\mathrm{Ca})}$. The sod-forming process on virgin land is not clearly manifested: A-horizon (AY) does not have a dark gray color and slowly passes into the horizon BEL. The available data on the lower boundaries of the genetic horizons, covering a large period (60 years), showed that the sod and podzolic process are in a comparatively dynamic equilibrium. The lower boundary of the humus horizon for the whole period of research was at a depth of $23-25 \mathrm{~cm}$. Such a slight variation does not enable us to confirm the dominance of the sod process.

The most significant indicator in the description of the soil profile is considered to be the boiling line, which is the upper boundary of the illuvial-carbonate horizon $\left(\mathrm{Bt}_{(\mathrm{Ca})}\right)$. In 1960 , the boiling line on the virgin plot was at a depth of $120 \mathrm{~cm}$ and in 60 years it fall to $130 \mathrm{~cm}$, which proves the existence of the leaching (decarbonization) of gray forest soil in Western Siberia.

AO $5 \mathrm{~cm}$. The forest litter is of a strong degree of decomposition. It consists of the fall of birch leaves, the remains of herbaceous plants and subshrubs.

AY -5-23 cm. Gray (Munsell color system: Hue 0N 6/0); the lower part of the horizon is light gray (Hue $0 \mathrm{~N} \mathrm{7/0).} \mathrm{Fresh,} \mathrm{middle} \mathrm{loamy,} \mathrm{lumpy-nuciform,} \mathrm{slightly} \mathrm{packed,} \mathrm{a} \mathrm{lot} \mathrm{of}$ roots, the switch is gradual.

BEL 23-32 cm. russet -light gray (Hue 10YR 6/2), fresh, middle loamy, nuciform, packed, spongy, silica powdering, a lot of roots

Bt $32-120 \mathrm{~cm}$. Russet (Hue 10YR 8/5), fresh, heavy loamy, nuciform, dense, roots. The switch is gradual, the presence of carbonates - clear.

$\mathrm{Bt}(\mathrm{Ca})$ 120-170 cm Light-russet, (Hue 10YR 7/6), fresh, middle loamy, tendernuciform, fine-pored, packed, roots (rarely), boils up from hydrochloric acid, carbonates in the form of veins. The switch is gradual.

C $>170 \mathrm{~cm}$. Yellow-fawn (Hue 5Y 8/3), moist, middle loamy, unstructured, thin-pored, packed, boils from hydrochloric acid.

Soil: gray forest middle loamy.

The morphological description of the sections in 1960, 1989 and 2019 showed that there are anthropogenic variations on the arable land. The plough-layer is marked by a lumpyblocky structure, which is not typical for virgin areas. The sole shoe is clearly highlighted at a depth of $22 \mathrm{~cm}$, which has a dark gray color and a heavy granulometric composition. The 
most significant anthropogenic change in morphological features is an increase in the carbonate depth. In 1960, the boiling line on the variants was fixed at $125-128 \mathrm{~cm}$ with a variation ranging from 115 to $140 \mathrm{~cm}$. By 2019, the carbonates on the virgin land fell to $130 \mathrm{~cm}$, which is $10 \mathrm{~cm}$ deeper than the original values. Considering the fact of spatial heterogeneity of the calcium carbonate depth, a considerable decrease in the boiling line was determined, which is typical for the gray forest soils of Western Siberia.

Table 1. The lower boundary depth of the genetic horizons of gray forest soil on virgin and arable land.

\begin{tabular}{|l|c|c|c|c|c|}
\hline \multirow{2}{*}{ Section } & \multicolumn{5}{|c|}{ Genetic horizons } \\
\cline { 2 - 6 } & $\mathbf{A Y}$ & $\mathbf{B E L}$ & $\mathbf{B t}$ & $\mathbf{B t}(\mathbf{C a})$ & C(Ca) \\
\cline { 2 - 6 } & Antecedent soil, 1960 (the description by L. N. Karetin) \\
\hline 1 (Virgin land) & $23 \pm 4$ & $32 \pm 2$ & $120 \pm 7$ & $170 \pm 3$ & $>170$ \\
\hline 2. (Arable land) & $25 \pm 2$ & $35 \pm 1$ & $128 \pm 5$ & $170 \pm 2$ & $>171$ \\
\hline 3 (Arable land) & $25 \pm 2$ & $33 \pm 2$ & $125 \pm 3$ & $168 \pm 5$ & $>172$ \\
\hline 4. (Arable land) & $25 \pm 3$ & $35 \pm 2$ & $127 \pm 7$ & $165 \pm 2$ & $>173$ \\
\hline & 1989 (the description by A. G. Karyakina) & $>175$ \\
\hline 1 (Virgin land) & $25 \pm 3$ & $35 \pm 3$ & $128 \pm 8$ & $175 \pm 2$ & $>175$ \\
\hline 2. (Arable land) & $22 \pm 2$ & $33 \pm 2$ & $131 \pm 10$ & $175 \pm 4$ & $>175$ \\
\hline 3 (Arable land) & $25 \pm 3$ & $32 \pm 3$ & $132 \pm 13$ & $175 \pm 2$ & $>172$ \\
\hline 4. (Arable land) & $25 \pm 3$ & $35 \pm 2$ & $130 \pm 12$ & $172 \pm 3$ & $>177$ \\
\hline & 2019 (the description by D. I. Eremin) \\
\hline 1 (Virgin land) & $25 \pm 5$ & $33 \pm 3$ & $130 \pm 8$ & $177 \pm 3$ & $>175$ \\
\hline 2. (Arable land) & $27 \pm 2$ & $37 \pm 3$ & $138 \pm 13$ & $175 \pm 5$ & $>176$ \\
\hline 3 (Arable land) & $27 \pm 3$ & $37 \pm 1$ & $135 \pm 15$ & $176 \pm 2$ & $>180$ \\
\hline 4. (Arable land) & $30 \pm 2$ & $35 \pm 2$ & $127 \pm 12$ & $180 \pm 1$ & \\
\hline
\end{tabular}

Note: section 2. - without the use of a fertilizer system; section 3 - mineral fertilizer system; section 4 - organic fertilizer system.

In 1989, the upper part of the illuvial-carbonate horizon on arable land was at a depth of $130-132 \mathrm{~cm}$, while on virgin land $-128 \pm 8 \mathrm{~cm}$. The statistical calculation revealed the noneffect of various fertilizer systems on the decarbonization processes of the gray forest soil profile, since the revealed deviations between arable and virgin land are unreliable.

By 2019, the morphological features of the arable horizon on the variants became visually noticeable. At the control, where mineral and organic fertilizers were not used, the structural condition became significantly worse - a lumpy structure with a very low degree of water resistance became noticeable. In the variant with an organic fertilizer system, the arable horizon was characterized by a loose consistence, a finely lumpy waterproof structure. The carbonate depth did not change over the period of 60 years and corresponded to $127 \pm 12 \mathrm{~cm}$. In the remaining variants, carbonates have decreased from 125-128 to 135 $138 \mathrm{~cm}$ over the years of research, thereby confirming the fact of increasing the leaching process when gray forest soils are involved in the arable fund [12,13].

The virgin gray forest soil of the sub-boreal zone of the Trans-Urals was characterized by a slightly acidic reaction and had no significant changes during the entire period of research. $\mathrm{pH}$ of the salt extract varied in the humus layer (AY) from 4.8 to 5.0 units, with an actual acidity of 5.4-5.6 units (tab.2). No significant changes were also detected in the $\mathrm{BEL}$ and $\mathrm{Bt}$ horizons on virgin land.

In 1960, the arable layer on the studied variants 2, 3 and 4 did not vary in actual and exchange acidity from virgin soil. By 1989, the lack of a fertilizer system had no effect on the acid-base characteristics of gray forest soil. The systematic use of mineral fertilizers 
resulted in an increase in the actual acidity - the $\mathrm{pH}$ values in the water extract reduced from 5.5 to 5.2 units. The exchange acidity also changed from 5.0 to 4.7 units, which indicates an adverse effect of mineral fertilizers. The acidifying effect is due to various influence mechanisms of fertilizers on arable soil. The widespread opinion is that mineral fertilizers are mostly physiologically acidic, for example, ammonium nitrate or potassium sulfate. There is data that mineral fertilizers increase the yield, and, therefore, the biogenic removal of alkaline earth metal cations, therefore strengthening the process of decalcification, which is expressed in an increase in the $\mathrm{pH}$ of the salt extract and a decrease in the amount of exchange bases [14]. Our previous studies have demonstrated that the annual use of nitrogen fertilizers can change the qualitative composition of humus towards the synthesis of fulvic acids, which have a pronounced acidifying effect [15]. In our opinion, the mechanism of acidification by increasing the biogenic removal of calcium and magnesium and enhancing the synthesis of fulvic acids is most topical for gray forest soils of the sub-boreal zone of the Trans-Urals.

Table 2. The dynamics of the actual ( $\mathrm{pH}_{2} \mathrm{O}$ ) exchange acidity $\left(\mathrm{pH}_{\mathrm{KCl}}\right)$ of a gray forest soil.

\begin{tabular}{|c|c|c|c|c|c|c|}
\hline \multirow{3}{*}{ Variants } & \multicolumn{3}{|c|}{$\mathrm{pH} 2 \mathrm{O}$} & \multicolumn{3}{|c|}{$\mathrm{pH}$} \\
\hline & $\mathbf{A Y} / \mathbf{P}$ & BEL & Bt & $\mathbf{A Y} / \mathbf{P}$ & BEL & Bt \\
\hline & \multicolumn{3}{|c|}{ Antecedent soil, 1960} & & & \\
\hline 1 (Virgin land) & 5.6 & 5.4 & 5.8 & 5.0 & 5.3 & 4.7 \\
\hline 2. (Arable land) & 5.5 & 5.2 & 5.6 & 5.0 & 5.2 & 4.5 \\
\hline 3 (Arable land) & 5.6 & 5.3 & 5.5 & 5.0 & 5.0 & 4.5 \\
\hline \multirow[t]{2}{*}{ 4. (Arable land) } & 5.5 & 5.4 & 5.5 & 4.8 & 5.2 & 4.5 \\
\hline & 1989 & & & & & \\
\hline 1 (Virgin land) & 5.6 & 5.4 & 5.7 & 4.8 & 5.3 & 4.5 \\
\hline 2. (Arable land) & 5.4 & 5.2 & 5.5 & 5.1 & 4.8 & 4.5 \\
\hline 3 (Arable land) & 5.2 & 5.0 & 5.5 & 4.7 & 4.5 & 4.5 \\
\hline \multirow[t]{2}{*}{ 4. (Arable land) } & 5.5 & 5.4 & 5.5 & 5.2 & 5.3 & 4.7 \\
\hline & 2019 & & & & & \\
\hline 1 (Virgin land) & 5.4 & 5.2 & 5.8 & 4.8 & 5.0 & 4.5 \\
\hline 2. (Arable land) & 5.5 & 5.3 & 5.3 & 5.0 & 5.0 & 4.7 \\
\hline 3 (Arable land) & 5.0 & 4.8 & 5.4 & 4.5 & 4.5 & 4.6 \\
\hline 4. (Arable land) & 5.6 & 5.7 & 5.5 & 5.8 & 5.7 & 5.2 \\
\hline
\end{tabular}

Note: section 2. - without the use of a fertilizer system; section 3 - mineral fertilizer system; section 4 - organic fertilizer system.

The organic fertilizer system (variant 4) gradually decreased the actual and exchange acidity. In the period from 1960 to 1989 , the $\mathrm{pH}$ values of the salt extract rose from 4.8 to 5.2 units, and by 2019 - to 5.8 units. Changes were also found in deeper layers. In the horizon $\mathrm{BEL}$ the value $\mathrm{pH}_{\mathrm{KCI}}$ has increased from 5.2 to 5.7 units in 59 years. Nevertheless, it should be noted that the decrease in the exchange acidity in this horizon was observed in the period from 1989 to 2019.

For establishing the mechanism of changing the acid-base characteristics of gray forest soil, a systematic analysis of the dynamics of the exchange base sum and hydrolytic acidity is required. The initial values (1960) varied in the AY and P horizons in the range: the sum of exchange bases - from 16.3 to $17.5 \mathrm{~mol}(\mathrm{eq}) / 100 \mathrm{~g}$ of soil; hydrolytic acidity 7.5-7.7 mol (eq)/100 g of soil, which corresponded to the average values of gray forest soils in Western Siberia (tab.3). In the podzolized horizon (BEL), these indicators were considerably lower. The illuvial horizon $(\mathrm{Bt})$ was characterized by a higher amount of exchange bases - 14.8- 
$16.4 \mathrm{~mol}(\mathrm{eq}) / 100 \mathrm{~g}$ of soil, while downgrading the hydrolytic acidity to $4.6-5.4 \mathrm{~mol}(\mathrm{eq}) / 100$ $\mathrm{g}$ of soil.

In the period from 1960 to 2019, no significant changes in the amount of exchange bases and hydrolytic acidity were observed in the virgin area. There is only a trend of gradual enrichment of the soil-absorbing complex with cations of alkaline earth metals and a hydrolytic acidity decrease.

No changes in the amount of exchange bases and hydrolytic acidity were observed on arable land where the fertilizer system was absent (variant 2), and the soil-absorbing complex was in a stable condition for 59 years.

The long-term use of mineral fertilizers (variant 3 ) resulted in a decrease in the amount of exchange bases in the period from 1960 to 1989 by $12 \%$ relative to the initial values. This is evidence of enhanced soil decalcification versus a stable increase in crop yields. A decrease in the amount of exchange bases was also registered in the Bt horizon, which, in our opinion, is the result of the same biogenic removal by plants.

In the period from 1989 to 2019, an increase in hydrolytic acidity in the BEL and Bt horizons started on the variant with a mineral fertilizer system. It is an adverse factor for the gray forest soils of Western Siberia, which are initially inclined to acidification. Since the hydrolytic acidity in the arable horizon (P) remained invariable during all the years of research, and the amount of exchange bases declined. This fact indicates the transformation process of the soil-absorbing complex and changes in the qualitative composition of humus. As a result, the formed humic substances of an acidic nature (mainly fulvic acids) begin to move deeper into the soil profile, therefore affecting the hydrolytic acidity of the deeper layers [14]. By 2019, the hydrolytic acidity in the BT and Bt horizons reached 6.7 and 6.4 $\mathrm{mol}(\mathrm{eq}) / 100 \mathrm{~g}$ of soil, which is 24 and $21 \%$ higher than the initial values.

The systematic use of organic fertilizers (variant 4) ensures not only the soil enrichment with carbon and nutrients, but also with cations of alkaline earth metals, mainly calcium and magnesium. Thus, the increase in crop yields does not result in the decalcification of gray forest soils. Consequently, an increase in the amount of exchange bases in the arable horizon was observed. It is being considered a favorable factor of anthropogenic impact against the background of a sufficient amount of soil organic matter. From 1960 to 2019, the amount of exchange bases increased from 16.4 to $20.4 \mathrm{~mol}(\mathrm{eq}) / 100 \mathrm{~g}$ of soil. The increase in this indicator started only in the period from 1989 to 2019.

Table 3. The sum dynamics of the exchange bases (S) and hydrolytic acidity (Hg) of gray forest soil, mol(eq)/100 $\mathrm{g}$ of soil.

\begin{tabular}{|c|c|c|c|c|c|c|}
\hline \multirow{3}{*}{ Variants } & \multicolumn{3}{|c|}{$\mathrm{S}$} & \multicolumn{3}{|c|}{$\mathrm{Hg}$} \\
\hline & $\mathbf{A Y} / \mathbf{P}$ & BEL & Bt & $\mathbf{A Y} / \mathbf{P}$ & BEL & Bt \\
\hline & \multicolumn{3}{|c|}{ Antecedent soil, 1960} & & & \\
\hline 1 (Virgin land) & 17.5 & 12.6 & 16.4 & 7.5 & 5.4 & 4.6 \\
\hline 2. (Arable land) & 16.3 & 10.7 & 15.2 & 7.5 & 5.7 & 5.3 \\
\hline 3 (Arable land) & 16.5 & 10.5 & 15.3 & 7.7 & 5.4 & 5.3 \\
\hline \multirow[t]{2}{*}{ 4. (Arable land) } & 16.4 & 10.5 & 14.8 & 7.6 & 5.5 & 5.4 \\
\hline & 1989 & & & & & \\
\hline 1 (Virgin land) & 17.8 & 10.6 & 17.3 & 7.3 & 5.2 & 4.0 \\
\hline 2. (Arable land) & 16.3 & 10.0 & 13.7 & 7.2 & 5.8 & 5.4 \\
\hline 3 (Arable land) & 14.6 & 10.3 & 13.4 & 7.9 & 6.6 & 5.7 \\
\hline \multirow[t]{2}{*}{ 4. (Arable land) } & 16.5 & 11.0 & 14.3 & 6.5 & 6.7 & 5.2 \\
\hline & 2019 & & & & & \\
\hline 1 (Virgin land) & 18.3 & 11.4 & 15.9 & 7.1 & 5.0 & 4.5 \\
\hline 2. (Arable land) & 16.2 & 10.4 & 12.1 & 7.6 & 6.0 & 5.3 \\
\hline
\end{tabular}




\begin{tabular}{|l|c|c|c|c|c|c|}
\hline 3 (Arable land) & 14.7 & 9.5 & 11.6 & 8.0 & 6.7 & 6.4 \\
\hline 4. (Arable land) & 20.4 & 14.3 & 12.4 & 6.8 & 5.2 & 4.8 \\
\hline
\end{tabular}

Note: section 2. - without the use of a fertilizer system; section 3 - mineral fertilizer system; section 4 - organic fertilizer system.

The integral indicator of the chemical properties of soils is considered to be the base (BEC) of exchange capacity and the degree of base saturation (V). The value of the cation exchange capacity characterizes the condition of the soil-absorbing complex and the colloidal fraction, which consists of active humus substances. A decrease in the capacity of cation exchange is a sign of the destruction of the organomineral matrix and the subsequent decrease in soil fertility.

Prior to the introduction of the experiment (1961), the initial soil was marked by BEC stability under variants and genetic horizons (Table 4). During the years of research on virgin land, no significant changes were observed. The deviations were within the measurement error.

In 1960, the arable gray forest soil differed from the virgin ones in terms of the degree of base saturation. For all horizons, this indicator was $2-5 \%$ lower than the cation exchange capacity, which is specific for anthropogenic-transformed soils.

From 1960 to 1989, the amount of exchange bases and the degree of saturation of the arable horizon with bases in the variant where mineral and organic fertilizer systems were not used remained at the same level: $24 \mathrm{~mol}(\mathrm{eq}) / 100 \mathrm{~g}$ of soil and $69 \%$ of the BEC. Yet changes have occurred in the BEL and Bt horizons. For 29 years, the degree of base saturation has reduced from 65 and 74 to 63 and $72 \%$ of the BEC. In the subsequent period (1989-2019), a decrease was detected only in the Bt horizon.

Therefore, it was found that in the conditions of Western Siberia, the leaching process, which is established by reducing the amount of exchange bases, appears in gray forest soils. Its long-term use in arable land enhances the leaching of calcium and magnesium cations from the soil-absorbing complex.

The mineral fertilizer system, which provided for the introduction of no more than $\mathrm{N}_{65} \mathrm{P}_{30} \mathrm{~kg} / \mathrm{ha}$ annually, it did not influence the soil-absorbing complex. The BEC remained constant for 59 years. Nevertheless, the biogenic removal of calcium and magnesium by the crop, followed by the replacement of the deficit by hydrogen and aluminum ions, resulted in a decrease in the degree of soil saturation with bases, which by 2019 reached $64 \%$ of the BEC. The maximum decrease happened in the subsurface horizons of BEL and Bt.

According to our research, in the conditions of the flushing regime, which is typical for the sub-boreal zone of Western Siberia, only an organic fertilizer system provides not only to stabilize the chemical properties of gray forest soils, but also to improve them. From 1960 to 2019 , the cation exchange capacity in the arable layer (P) raised by $13 \%$ compared to the initial values and reached $27 \mathrm{~mol}(\mathrm{eq}) / 100 \mathrm{~g}$ of soil. This had a positive effect on the degree of base saturation, which raised from 68 to $75 \%$ of the $\mathrm{BEC}$, composing the conversion of arable land from the category of those in need to liming.

Table 4. Base exchange capacity (BEC) and the degree of base saturation (V) of a gray forest soil.

\begin{tabular}{|c|c|c|c|c|c|c|}
\hline \multirow{3}{*}{ Variants } & \multicolumn{3}{|c|}{$\begin{array}{c}\mathrm{BEC}, \\
\mathrm{mol}(\mathrm{eq}) / 100 \mathrm{~g} \text { of soil }\end{array}$} & \multicolumn{3}{|c|}{$\mathrm{V}, \%$ from $\mathrm{BEC}$} \\
\hline & $\mathbf{A Y} / \mathbf{P}$ & BEI & Bt & $\mathbf{A Y} / \mathbf{P}$ & BEL & Bt \\
\hline & \multicolumn{3}{|c|}{ Antecedent soil, 1960} & & & \\
\hline 1 (Virgin land) & 25 & 18 & 21 & 70 & 70 & 78 \\
\hline 2. (Arable land) & 24 & 16 & 21 & 68 & 65 & 74 \\
\hline 3 (Arable land) & 24 & 16 & 21 & 68 & 66 & 74 \\
\hline 4. (Arable land) & 24 & 16 & 20 & 68 & 66 & 73 \\
\hline
\end{tabular}




\begin{tabular}{|l|c|c|c|c|c|c|}
\hline & 1989 & & & & & \\
\hline 1 (Virgin land) & 25 & 16 & 21 & 71 & 67 & 81 \\
\hline 2. (Arable land) & 24 & 16 & 19 & 69 & 63 & 72 \\
\hline 3 (Arable land) & 23 & 17 & 19 & 65 & 61 & 70 \\
\hline 4. (Arable land) & 23 & 18 & 20 & 72 & 62 & 73 \\
\hline & 2019 & & & & & \\
\hline 1 (Virgin land) & 25 & 16 & 20 & 72 & 70 & 78 \\
\hline 2. (Arable land) & 24 & 16 & 17 & 68 & 63 & 70 \\
\hline 3 (Arable land) & 23 & 16 & 18 & 65 & 59 & 64 \\
\hline 4. (Arable land) & 27 & 20 & 17 & 75 & 73 & 72 \\
\hline
\end{tabular}

Note: section 2. - without the use of a fertilizer system; section 3 - mineral fertilizer system; section 4 - organic fertilizer system.

In the podzolized horizon (BEL), a stable improvement in the degree of base saturation was observed from 68 to $75 \%$ of the BEC, while in other variants, this indicator has reduced. Therefore, it was found that the use of an organic fertilizer system gradually enhances the capacity of cation exchange and the degree of base saturation.

\section{Conclusion}

The abandonment of the mineral and organic fertilizer system resulted in a deterioration of the structural condition of the arable gray forest soil. In 60 years, the arable horizon has acquired a lumpy structure with a very low degree of water resistance. In the variant with an organic fertilizer system, the arable horizon became finely lumpy and was marked by a crumbly addition. The virgin gray forest soils of Western Siberia are slightly acidic and their acid-base feature has not changed for a long time. The inclusion of these soils in the farming business and the long-term use of mineral fertilizers results in the acidification of the main genetic horizons due to the combined effect of the biogenic removal of calcium and magnesium, as well as through the deterioration of the quality of humus substances. The organic fertilizer system has a positive effect on the chemical properties of gray forest soil.

\section{References}

1. A.V Lyubimova, G.V. Tobolova, D.I. Eremin, I.G. Loskutov, Vav J of Gen and Br, 24 (2), 123-130 (2020) DOI 10.18699/VJ20.607.

2. D. Eremina, IT-technologies in soil Informatics and Russian agribusiness, St. Petersburg, EDP Sciences, 04016, (2018) DOI 10.1051/matecconf/201817004016.

3. A.A. Kazak, An of Ag Bio Res, 24 (2), 174-182 (2019)

4. Y.P. Loginov, An of Ag Bio Res, 24 (1), 76-81 (2019)

5. A.S. Motorin, IOP Conf Ser: Ear \& Env Sc, 8, 082026 (2018) DOI 10.1088/17551315/194/8/082026.

6. D.V. Eremina, IOP Conference Series: Earth and Environmental Science, 012173, (2019) DOI 10.1088/1755-1315/403/1/012173.

7. D.I. Eremin, Eur S Sc, 49(5), 538-545 (2016) DOI 10.1134/S1064229316050033.

8. N. Gruzdeva, IOP Conference Series: Earth and Environmental Science, 012174, (2019) DOI 10.1088/1755-1315/403/1/012174. 
9. S. Sherstobitov, IOP Conference Series: Materials Science and Engineering 62011, (2019) DOI 10.1088/1757-899X/537/6/062011.

10. O.A. Sorokina, Eur S Sc, 39(8), 813-819 (2016) DOI 10.1134/S1064229306080023.

11. M. Kastornova, Adv in Eng Res, 151, DOI: 10.2991/agrosmart-18.2018.59

12. A.V. Chelovechkova, J of En Man \& T, 9, 3 (27), 485-490 (2018) DOI 10.14505/jemt.v9.3(27).08.

13. A.V. Chelovechkova, IOP Conference Series: Earth and Environmental Science 012017, (2021) DOI 10.1088/1755-1315/720/1/012017.

14. V.V. Kotov, K. E. Stekolnikov, S. V. Tkachenko, Eur S Sc, 37(6), 618-623 (2004)

15. V.A. Khmelev, A.A. Tanasienko, Con Prob of Ec, 2(6), 631-641 (2009) DOI 10.1134/S1995425509060228. 